\title{
Stimulation der TSH-Sekretion durch TRF-Belastung bei hypothalamischen und hypophysären Krankheitsbildern
}

\author{
C. R. Pickardt, W. Geiger, R. Fahmbusch und P. C. Scriba* \\ II. Medizinische Klinik (Direktor: Prof. Dr. E. Buchborn), I. Frauenklinik (Direktor: Prof. Dr. J. Zander) \\ und Neurochirurgische Klinik (Direktor: Prof. Dr. F. Marguth) der Universität München
}

\begin{abstract}
Stimulation of TSH Secretion by TRF in Hypothalamic and Pituitary Disease.

Summary. 1. The response of the serum TSH levels after i.v. administration of $500 \mu \mathrm{g}$ TRF have been determined in normal controls $(n=8)$ and in 37 patients with pituitary tumour or hypothalamic disease.

2. Following hypophysectomy in patients with intrasellar tumours $(n=12)$, the increment in TSH levels after TRF was absent or diminished.

3. Secondary hypothyroidism was found pre-operatively in 3 of 9 patients with intrasellar pituitary adenoma. In these 3 patients, however, a normal TSH response to TRF was found. This result diminishes the diagnostic value of the TRF test regarding the distinction of pituitary and hypothalamic secondary hypothyroidism. A normal TSH response was found, as expected, in the 6 euthyroid patients of this group.

4. The TSH response was found to be normal or elevated in all but one of 7 patients with secondary hypothyroidism due to suprasellar tumour or hypothalamic disease. Primary hypothyroidism is also characterized by an increased TSH response and has to be excluded.

5. Among the patients with active $(n=7)$ or treated $(n=6)$ acromegaly, increased TSH response was found twice, i.e. in one patient of each of the two groups. In both patients, primary hypothyroidism could be excluded. The relevance of this increased TSH response for goitrogenesis in acromegaly is discussed.
\end{abstract}

Key words: Hypothalamic disease, pituitary tumours, pituitary insufficiency, secondary hypothyroidism, thyrotropin (TSH), thyrotropin releasing factor (TRF).

Zusammenfassung. 1. Die Antworten der Serum-TSHSpiegel (Thyreoidea-stimulierendes Hormon) auf TRF-In- jektion (Thyrotropin Releasing Factor) bei 8 Normalpersonen und 37 z.T. zweimal untersuchten Patienten mit hypophysärer oder hypothalamischer Erkrankung werden mitgeteilt.

2. Hypophysektomierte Patienten mit intrasellären Tumoren $(N=12)$ zeigten keine oder nur subnormale Anstiege der TSH-Spiegel.

3. Von 9 präoperativ untersuchten Patienten mit intrasellärem HVL-Adenom hatten 3 eine sekundäre Hypothyreose. Diese 3 reagierten dennoch mit einem normalen Anstieg der TSH-Spiegel. Dieser Befund schränkt die diagnostische Wertigkeit der TRF-Belastung zur Differenzierung hypophysärer und hypothalamischer sekundärer Hypothyreosen ein. Die 6 euthyreoten Patienten dieser Gruppe zeigten erwartungsgemäß einen normalen TSH-Anstieg.

4. Bei den Patienten mit sekundärer Hypothyreose bei suprasellärem Tumor oder hypothalamischer Erkrankung $(N=7)$ fand sich mit einer Ausnahme ein normaler oder ein erhöhter TSH-Anstieg. Die Bedeutung des Ausschlusses einer primären Hypothyreose wurde dargestellt, da diese Erkrankung ebenfalls durch erhöhte TSH-Anstiege bei TRF-Belastung charakterisiert ist.

5. Je ein Patient aus der Gruppe der aktiven $(N=7)$ und der behandelten $(N=6)$ Akromegalie zeigten einen nioht auf eine primäre Hypothyreose zurückführbaren erhöhen TSHAnstieg, dessen Rolle für das gehäufte Auftreten einer Struma bei Akromegalie zu diskutieren ist.

Schlüsselwörter: Hypothalamische Erkrankungen, Нуроphysentumoren, Hypophysenvorderlappeninsuffizienz, Sekundäre Hyperthyreose, Thyreotropin (TSH), Thyrotropin Releasing Faktor (TRF).

\section{Einleitung}

Nachdem die Aufklärung der Struktur und die Synthese des Thyrotropin Releasing Factor (TRF) kürzlich gelungen ist $[1-4]$, steht jetzt das erste synthetische hypothalamische hypophyseotrope Hormon für die Anwendung in der klinischen Diagnostik zur Verfügung. Aus den bisher erschienenen Mitteilungen [5-10] lassen sich vorläufig folgende Regeln für die diagnostische Anwendung von TRF ableiten:

1. Die spezifische prompte Steigerung der Serumspiegel von Thyreoideastimulierendem Hormon (TSH) durch eine TRF-Injektion, mit der radioimmunologischen TSH-Bestimmung gemessen, ist diagnostisch der Beobachtung peripherer Parameter, z.B. Thyroxin-Bestimmung, vorzuziehen [5-9].

2. Die primäre (thyreogene) Hypothyreose weist im Vergleich mit Schilddrüsengesunden einen erhöhten

* Mit Unterstützung der Deutschen Forschungsgemeinschaft (Sonderforschungsbereich 51).
Anstieg der TSH-Spiegel nach TRF-Belastung auf, auch bei latenter ,präklinischer" Hypothyreose $[6,7]$.

3. Bei Hyperthyreose sind die Ausgangs-TSHSpiegel erniedrigt und fehlt die Stimulation der TSHSekretion durch TRF, so daB eine TSH-Antwort auf eine TRF-Belastung gegen eine Schilddrüsenüberfunktion spricht [5-8].

Über den naheliegenden Einsatz des TRF zur Differentialdiagnose zwischen hypophysär und hypothalamisch bedingter sekundärer Hypothyreose ist bislang nur anhand von wenigen Patienten berichtet worden [5-10]. Die vorliegende Arbeit sollte den Wert der TRF-Belastung für diese wichtige diagnostische Fragestellung kritisch analysieren. Dazu wurden bei 37 Patienten mit hypophysären und hypothalamischen Erkrankungen ${ }^{1}$ 42 TRF-Belastungen durch-

1 Für die Úberlassung der histologischen Diagnosen danken wir Herm Prof. Dr. med. O. Stochdorph, Abteilung für Neuropathologie, Pathologisches Institut der Universität
München. 
geführt. Vorläufige Ergebnisse dieser Arbeit wurden bereits vorgetragen [11].

\section{Methodik}

Die PB ${ }^{127}$ I-Bestimmung [12] und die Durchführung des $T_{3}$-in vitro-Tests [13] erfolgten wie beschrieben. Für die radioimmunologische Bestimmung von TSH-Spiegeln mit der Doppelantikörpermethode $[14,15]$ wurden HTSH und Anti-HTSH-Serum (Kaninchen) des NIAMD, BETHESDA, verwendet. Als Standard diente der HTSH-Research-Standard A des NIMR, Mill Hill, London. Die Berechnung der Integrale der TSH-Werte nach TRF-Belastung ist in der Legende zu Abb. 2 beschrieben.

Die stationären Patienten erhielten unter Grundumsatzbedingungen nach zweimaliger Blutabnahme $(-15 \mathrm{~min}$ und $-5 \mathrm{~min}$ ) um 9.00 Uhr $500 \mu \mathrm{g}$ TRF (L-Pyroglutamyl-Lhistidyl-L-prolinamid ${ }^{2}$ ) als schnelle i.v. Injektion. Weitere Blutentnahmen erfolgte zu den in Abb. 1 angegebenen Zeit. punkten. Die Seren wurden bis zur Messung bei $-37^{\circ} \mathrm{C}$ aufbewahrt.

Als Normalpersonen wurden stationäre Patienten ohne wesentlichen krankhaften Befund und ohne Übergewicht ausgewählt. Vier der 8 Nomalpersonen hatten geringfügige diffuse Strumen ohne klinische Zeichen oder Laborbefunde für eine primäre Hypothyreose. In den Tabelien 1-4 finden sich Angaben zur Klinik der untersuchten Patienten: Ein sekundärer Hvpogonadismus wurde nach den Werten der LH-Ausscheidung im 24 Std-Urin [16], nach den früher mitgeteilten LH-Werten im Serum [11] und nach dem klinischen Befund diagnostiziert. Für die Diagnose einer sekundären NNRInsuffizienz wurde das Ergebnis der ACTH-Belastung [17], gelegentlich auch der Insulin-Belastung herangezogen. NNRinsuffiziente Patienten wurden von der Cortisol-Substitution abgesetzt und falls erforderlich, mindestens 2 Tage vor der

2 Wir danken den Farbwerken Hoechst AG für die Uberlassung der Substanz Hoe 50011.
TRF-Belastung mit Dexamethason $2 \times 0,25 \mathrm{mg}$ substituiert Eine eventuelle Substitution mit Schilddrüsenhormonen bei Hypothyreose wurde mindestens 1 Woche vor der TREBelastung abgesetzt, mit Ausnahme der Patienten B. K. M. G. und A.H. (Tabelle $1 \mathrm{~b}$ ), welche bis $24 \mathrm{Std}$ vor dem Test Novothyral $\mathbb{B}^{\circ}$ erhielten.

Nebenwirkungen der TRF-Injektion, wie flüchtige Kopfschmerzen, Urindrang oder Übelkeit waren geringfügig und selten.

\section{Ergebnisse}

\section{Stimulation der TSH-Sekretion durch TRF-Injektion bei Normalpersonen}

Die Normalpersonen ( $N=8)$ zeigen nach Belastung mit TRF bereits nach 5 min einen Anstieg ihres Serum-TSH-Spiegels, der in 5 von 8 Fällen in der 30. min sein Maximum erreicht (Abb. 1, Tabelle 5). Bei den übrigen 3 Personen liegen die Maxima des TSH-Anstieges bereits in der 20. min. Im Mittel steigen die TSH-Spiegel von $3,95 \pm 1,82 \mu \mathrm{U} / \mathrm{ml}(x \pm s)$ vor der Injektion auf $11,18 \pm 3,27 \mu \mathrm{U} / \mathrm{ml} 30 \mathrm{~min}$ nach der Injektion (Abb. 1a). Zur 60. min fallen die TSHSpiegel bereits wieder ab und sind nach 120 min noch etwas erhöht. Nach 24 Std sind die Ausgangswerte wieder erreicht. - Der mittlere relative Anstieg der TSH-Spiegel $30 \mathrm{~min}$ nach TRF-Injektion beträgt etwa $200 \%$ (Abb. 1 b).

Erfaßt man den gesamten TSH-Anstieg nach TRF mit dem Integral der bis zur 120. min gemessenen Spiegel (Abb. 2), so findet man bei diesen 8 Normalpersonen als minimalen Anstieg $221 \mu \mathrm{U} \times \mathrm{ml}^{\mathbf{1}} \times \min$ und als maximalen Anstieg $1462 \mu \mathrm{U} \times \mathrm{ml}^{-1} \times \min$. Der

Tabellen 1-4. Einzelwerte für die basalen TSH-Spiegel, das Integral des TSH-Anstiegs nach Stimulation durch TRF, proteingebundenes Jod i.S. $\left(P B^{127} I\right)$. sog. freies $T_{3}{ }^{125} J$ und Index der freien Schilddrüsenhormone

Der basale TSH-Spiegel ist der Mittelwert der beiden Einzelwerte $15 \mathrm{~min}$ und $5 \mathrm{~min}$ vor Injektion von 500 $\mu \mathrm{g}$ TRF. Die Berechnung des Integrals des Anstiegs der TSH-Spiegel nach TRF ist der Legende zu Abb. 2 zu entnehmen. PB ${ }^{127}$ [12]: normal 3,1-6,8 $\mu \mathrm{g} \%$; sog. freies $T_{3}{ }^{-125} \mathrm{~J}$ [13]: normal $32-42 \%$. Der Index des freien Schilddrüsenhormons ist das Produkt aus proteingebundenem Jod i. S. und dem sog. freien $\mathrm{T}_{3}{ }^{-125} \mathrm{~J}: \mathrm{PBI} \times \mathrm{T}_{3}$ normal $1,33-2,50 \mu \mathrm{g} \%$ [13]

Tabelle 1. Vorwiegend intrasellër wachsende Tumoren

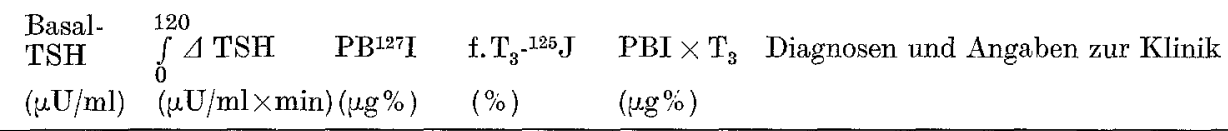

W. E.,, 48 J, 2,85

$154 \mathrm{~cm}, 67 \mathrm{~kg}$

S. H., 今, 54 J., $\quad 4,70$ $180 \mathrm{~cm}, 81 \mathrm{~kg}$

S. J., ఫิ, 51 J., $\quad 2,35$ $187 \mathrm{~cm} ., 75 \mathrm{~kg}$

M. K., ô, 43 J., $\quad 2,30$ $172 \mathrm{~cm} ., 97 \mathrm{~kg}$

W. P., 今゙, 21 J., $\quad 4,30$ $176 \mathrm{~cm} ., 68 \mathrm{~kg}$
501

508

5,6

39,0

2,18

a) Hormonell inaktive HVL-Adenome präoperativ

$4,4 \quad 33,9 \quad 1,49 \quad$ keine sek. NNR-Insuffizienz, keine sek. Hypothyreose, sek. Hypogonadismus. Sella vergrößert, Chiasmasyndrom

keine sek. NNR-Insuffizienz, keine sek. Hypothyreose (autonomes Adenom), sek. Hypogonadismus.

Sella vergrößert, Chiasmasyndrom

sek. NNR-Insuffizienz, sek. Hypothyreose, kein sek. Hypogonadismus.

Sella vergrößert, Chiasmasyndrom

$\begin{array}{llll}485 & 4,2 & 32,7 & 1,37\end{array}$

421

$3,9 \quad 30,4 \quad 1,19$

keine sek. NNR-Insuffizienz, keine sek. Hypothyreose, sek. Hypogonadismus. Sella vergrößert, Chiasmasyndrom

keine sek. NNR-Insuffizienz, sek. Hypothyreose, sek. Hypogonadismus. Sella vergrößert, Chiasmasyndrom 
Tabelle 1 (Fortsetzung)

\begin{tabular}{|c|c|c|c|c|c|c|}
\hline & $\begin{array}{l}\text { Basal- } \\
\text { TSH } \\
(\mu \mathrm{U} / \mathrm{ml})\end{array}$ & $\begin{array}{l}\int_{0}^{120} \Delta \mathrm{TSH} \\
(\mu \mathrm{U} / \mathrm{ml} \times \min \end{array}$ & $\begin{array}{l}\mathrm{PB}^{127 \mathrm{I}} \\
\text { a) }(\mu \mathrm{g}-\%)\end{array}$ & $\begin{array}{l}f \cdot T_{3} \cdot{ }^{125} \mathrm{~J} \\
(\%)\end{array}$ & $\begin{array}{l}\mathrm{PBI} \times \mathrm{T}_{3} \\
(\mu \mathrm{g}-\%)\end{array}$ & Diagnosen und Angaben zur Klinik \\
\hline $\begin{array}{l}\text { F. G., J, } 39 \mathrm{~J} . \\
164 \mathrm{~cm}, 58 \mathrm{~kg}\end{array}$ & 3,25 & 1489 & 3,8 & 30,0 & 1,14 & $\begin{array}{l}\text { sek. NNR-Insuffizienz, sek. Hypothyreose, sek. } \\
\text { Hypogonadismus. } \\
\text { Sella vergrößert, Chiasmasyndrom }\end{array}$ \\
\hline $\begin{array}{l}\text { B. H., } 0,44 \mathrm{~J} ., \\
173 \mathrm{~cm}, 71 \mathrm{~kg}\end{array}$ & 2,40 & 585 & 3,9 & 39,7 & 1,45 & $\begin{array}{l}\text { keine sek. NNR-Insuffizienz, keine sek. Hypo- } \\
\text { thyreose, sek. Hypogonadismus. } \\
\text { Sella vergrößert, Chiasmasyndrom }\end{array}$ \\
\hline $\begin{array}{l}\text { G. H. J., A, } 25 \mathrm{~J} . \\
168 \mathrm{~cm}, 87 \mathrm{~kg}\end{array}$ & 4,80 & 302 & 4,8 & 29,5 & 1,41 & $\begin{array}{l}\text { keine sek. NNR-Insuffizienz, keine sek. Hypo- } \\
\text { thyreose, sel. Hypogonadismus. } \\
\text { Sella vergrößert, Chiasmasyndrom }\end{array}$ \\
\hline $\begin{array}{l}\text { E. K., },, 51 \mathrm{~J} ., \\
160 \mathrm{~cm}, 66 \mathrm{~kg}\end{array}$ & 3,50 & 552 & 4,4 & 34,1 & 1,50 & $\begin{array}{l}\text { sek. NNR-Insuffizienz, keine sek. Hypothyreose, } \\
\text { kein sek. Hypogonadismus. } \\
\text { Sella vergrößert, Chiasmasyndrom, Rezidiv eines } \\
\text { chromophoben HVL-Adenoms }\end{array}$ \\
\hline
\end{tabular}

B. K., ㅅ, 55 J., $\quad 3,95 \quad-18$

$173 \mathrm{~cm}, 80 \mathrm{~kg}$

M. G., ơ, 23 J., $\quad 3,60$

$166 \mathrm{~cm}, 60 \mathrm{~kg}$

\begin{tabular}{|c|c|c|c|c|c|}
\hline $\begin{array}{l}\text { A. H. } 63 \mathrm{~J} . \mathrm{J} \\
161 \mathrm{~cm}, 66 \mathrm{~kg}\end{array}$ & 3.70 & 46 & 2,8 & 28,9 & 0,81 \\
\hline $\begin{array}{l}\text { Sp. M., P, } 59 \mathrm{~J} ., \\
154 \mathrm{~cm}, 68 \mathrm{~kg}\end{array}$ & 4,20 & 33 & 3,2 & 31,6 & 1,01 \\
\hline $\begin{array}{l}\text { W. E., } 9,48 \mathrm{~J} . \\
154 \mathrm{~cm}, 79 \mathrm{~kg}\end{array}$ & 4,10 & 66 & 5,2 & 37,8 & 1,97 \\
\hline $\begin{array}{l}\text { R. F., o, } 40 \mathrm{~J} ., \\
182 \mathrm{~cm}, 76 \mathrm{~kg}\end{array}$ & 3,15 & 276 & 3,8 & 31,9 & 1,21 \\
\hline $\begin{array}{l}\text { S. H., o, } 54 \text { J., } \\
180 \mathrm{~cm}, 70 \mathrm{~kg}\end{array}$ & 1,85 & 213 & 4,3 & 34,2 & 1,47 \\
\hline $\begin{array}{l}\text { W. P., } \\
178 \mathrm{~cm}, 81 \mathrm{~kg} .\end{array}$ & 3,40 & 247 & 2,4 & 29,9 & 0,71 \\
\hline
\end{tabular}

$293 \quad 2,6 \quad 29,6 \quad 0,77$

b) Hormonell inaktive HVL-Adenome postoperativ

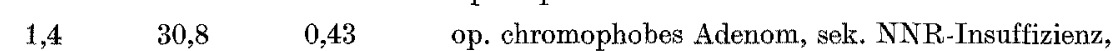
sek. Hypothyreose, sek. Hypogonadismus. Sella vergrößert, Chiasmasyndrom

inkompl. op. chromophobes Adenom, sek. NNRInsuffizienz, sek. Hypothyreose, sek. Hypogonadismus. Sella vergrößert, Chiasmasyndrom

op. chromophobes Adenom, sek. NNR-Insuffizienz, sek. Hypothyreose, sek. Hypogonadismus.

Sella vergrößert, Chiasmasyndrom

op. chromophobes Adenom, sek. NNR-Insuffizienz, sek. Hypothyreose, sek. Hypogonadismus, transit. D. insip.

Sella vergößert, Chiasmasyndrom

op. HVL-Ai'enom, sek. NNR-Insuffílenz, keine seik. Hypothyreose, sek. Hypogonadismus Sella vergrößert, Chiasmasyndrom

op. chromophobes Adenom, sek. NNR-Insuffizienz, sek. Hypothyreose, sek. Hypogonadismus. Sella vergrößert, Chiasmasyndrom

op. Mischtypadenom, sek. NNR-Insuffizienz, autonomes Adenom der Schilddrüse, sek. Hypogonadismus.

Sella vergrößert, Chiasmasyndrom

op. fetales Adenom der Hypophyse, sek. NNR-Insuffizienz, sek. Hypothyreose, sek. Hypogonadismus Sella vergrößert, Chiasmasyndrom

\begin{tabular}{|c|c|c|c|c|c|}
\hline \multicolumn{6}{|c|}{ 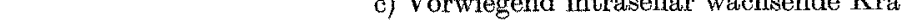 } \\
\hline $\begin{array}{l}\text { K. R., }, 16 \mathrm{~J} . \\
150 \mathrm{~cm}, 40 \mathrm{~kg}\end{array}$ & 6,10 & 9 & 3,6 & 37,6 & 1,36 \\
\hline $\begin{array}{l}\text { E. K., o, 37 J. } \\
170 \mathrm{~cm}, 69 \mathrm{~kg}\end{array}$ & 2,80 & -11 & 2,4 & 37,6 & 0,90 \\
\hline $\begin{array}{l}\text { St. K., }, 22 \mathrm{~J} . \\
174 \mathrm{~cm}, 113 \mathrm{~kg}\end{array}$ & 2,20 & -64 & 1,6 & 30,9 & 0,49 \\
\hline $\begin{array}{l}\text { St. L., ð, } 30 \text { J., } \\
172 \mathrm{~cm}, 83 \mathrm{~kg}\end{array}$ & 2,35 & 107 & 1,8 & 30,4 & 0,55 \\
\hline
\end{tabular}

c) Vorwiegend intrasellär wachsende Kraniopharyngeome postoperativ op. Kraniopharyngeom, sek. NNR-Insuffizienz, Verd. sek. Hypothyreose, prim. Amenorrhoe. Sella vergrößert, Chiasmasyndrom

op. Kraniopharyngeom, sek. NNR-Insuffizienz, sek. Hypothyreose, sek. Hypogonadismus. Sella vergrößert, Chiasmasyndrom

inkompl. op. Kraniopharyngeom sek. NNR-Insuffizienz, sek. Hypothyreose, sek. Hypogonadismus, D. insip.

Sella obere Normgrenze, Chiasmasyndrom inkompl. op. Kraniopharyngeom, sek. NNR-Insuffizienz, sek. Hypothyreose, sek. Hypogonadismus, part. D. insip. Sella vergrößert, Chiasmasyndrom 

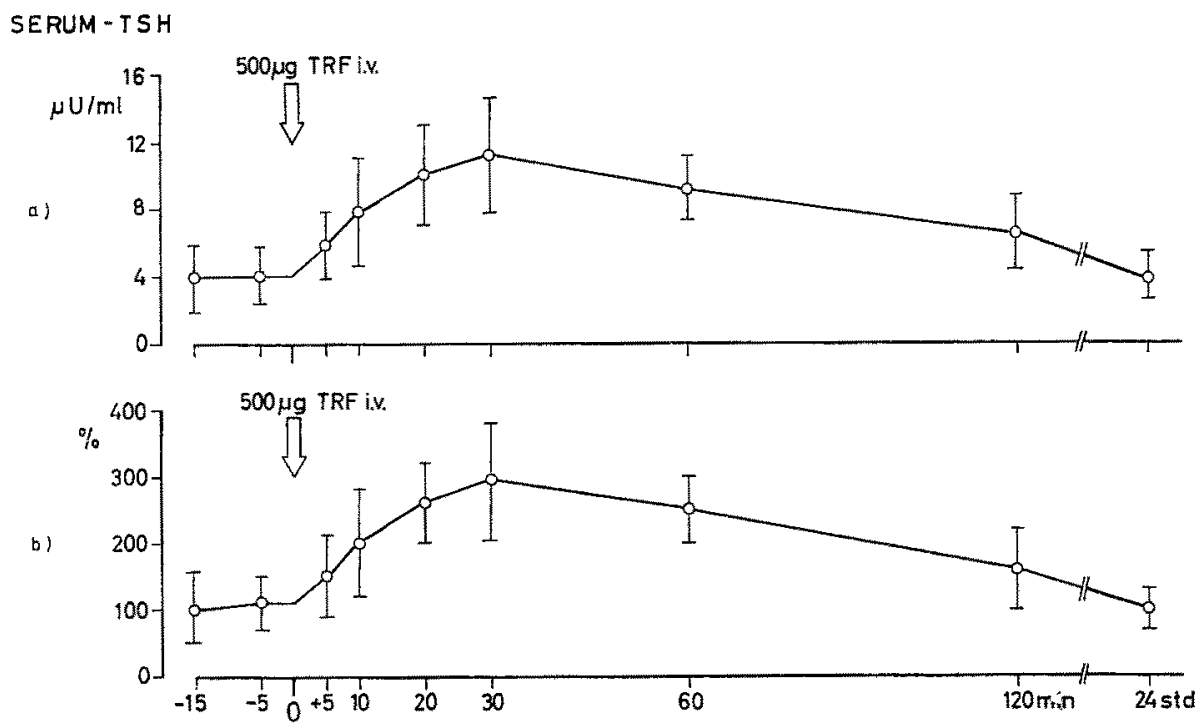

Abb. 1. a Kinetik des Serum-TSH-Spiegels über 24 Std nach schneller Injektion von $500 \mu \mathrm{g}$ TRF bei 8 Normalpersonen $(\bar{x} \pm s)$. b Prozentualex Anstieg der Serum-TSH-Spiegel der 8 Normalpersonen nach Injektion von $500 \mu \mathrm{g}$ TRF $(\bar{x} \pm s)$. Als Ausgangswert wurde der Mittelwert der 8 Einzelwerte $15 \mathrm{~min}$ vor der Injektion gewählt $(=100 \%)$

Tabelle 2. Suprasellär wachsende Tumorer und hypothalamische Erkrankungen

\begin{tabular}{|c|c|c|c|c|c|c|}
\hline & $\begin{array}{l}\text { Basal } \\
\text { TSH } \\
(\mu \mathrm{U} / \mathrm{ml})\end{array}$ & $\begin{array}{l}\int_{0}^{120} \Delta \mathrm{TSH} \\
(\mu \mathrm{U} / \mathrm{ml} \times \min )\end{array}$ & $\begin{array}{l}\operatorname{PB}^{127} \mathrm{I} \\
(\mu g-\%)\end{array}$ & $\begin{array}{l}\text { f. } T_{\mathrm{g}}{ }^{125} \mathbf{J} \\
(\%)\end{array}$ & $\begin{array}{l}\mathrm{PBI} \times \mathrm{T}_{3} \\
(\mu \mathrm{g}-\%)\end{array}$ & Diagnosen und Angaben zur Klinik \\
\hline \multicolumn{7}{|c|}{ a) Vorwiegend suprasellär wachsende Kraniopharyngeome } \\
\hline $\begin{array}{l}\text { M. J., } 9,17 \mathrm{~J} ., \\
140 \mathrm{~cm}, 44 \mathrm{~kg}\end{array}$ & 3,45 & 4107 & 3,1 & 35,8 & 1,11 & $\begin{array}{l}\text { op. suprasell. Kraniopharyngeom, keine selk. } \\
\text { NNR-Insuffizienz, sek. Hypothyreose, prim. } \\
\text { Amenorrhoe, kein HGH nachweisbar. } \\
\text { Sella normal groB, Chiasmasyndrom }\end{array}$ \\
\hline $\begin{array}{l}\text { F. U., },, 18 \mathrm{~J} ., \\
126 \mathrm{~cm}, 28 \mathrm{~kg}\end{array}$ & 3,20 & 288 & 2,2 & 32,1 & 0,71 & $\begin{array}{l}\text { op. suprasell. Kraniopharyngeom, keine sek. } \\
\text { NNR-Insuffizienz, sek. Hypothyreose, prim. } \\
\text { Amenorrhoe, keine HGH- nachweisbar. } \\
\text { Sella gering vergrößert, Chiasmasyndrom }\end{array}$ \\
\hline \multicolumn{7}{|c|}{ b) Hypothalamische Erkrankungen } \\
\hline $\begin{array}{l}\text { v.M, A., o, } 17 \mathrm{~J}_{.,} \\
160 \mathrm{~cm}, 51 \mathrm{~kg}\end{array}$ & 2,20 & 1422 & 3,8 & 29,5 & 1,12 & $\begin{array}{l}\text { Arachnitis optico-chiasmatica, sek. NNR- } \\
\text { Insuffizienz, sek. Hypothyreose, sek. Hypo- } \\
\text { gonadismus, part. D. insip., cerebrale Hyper- } \\
\text { natriämie }\end{array}$ \\
\hline & 1,15 & 816 & 4,2 & 28,9 & 1,21 & Cortisol-Subst., Tegretal-Behandlg. \\
\hline $\begin{array}{l}\text { G. J., o, } 27 \mathrm{~J} ., \\
178 \mathrm{~cm}, 83 \mathrm{~kg}\end{array}$ & 6,15 & 2513 & 3,7 & 32,6 & 1,21 & $\begin{array}{l}\text { suprasell. ungeklärte Erkrankung. sek, NNR- } \\
\text { Insuffizienz, sek. Hypothyreose, sek. Hypo- } \\
\text { gonadismus, keine D. insip. } \\
\text { Sella normal groß, transit. Skotom }\end{array}$ \\
\hline $\begin{array}{l}\text { H. G., o, } 29 \mathrm{~J} . \text {, } \\
160 \mathrm{~cm}, 79 \mathrm{~kg}\end{array}$ & 3,90 & 71 & 3,5 & 33,9 & 1,19 & $\begin{array}{l}\text { Hirneigener Tumor, Zustand n. Bestrahlung, sek. } \\
\text { NNR-Insuffizienz, sek. Hypothyreose, sek. Hypo- } \\
\text { gonadismus, D. insip. } \\
\text { Sella normal groß, Chiasmasyndrom }\end{array}$ \\
\hline $\begin{array}{l}\text { Mo., J., ㅇ, } 25 \mathrm{~J} ., \\
174 \mathrm{~cm}, 57 \mathrm{~kg}\end{array}$ & 5,95 & 1705 & 1,6 & 21,1 & 0,33 & $\begin{array}{l}\text { suprasell. ungeklärte Erkrankung. Keine sek. NNR- } \\
\text { Insuffizienz, sek. Hypothyreose, sek. (?) Hypo- } \\
\text { gonadismus, kein D. insip. } \\
\text { Sella normal groß, kein Chiasmasyndrom }\end{array}$ \\
\hline $\begin{array}{l}\text { K. F., J, } 62 \mathrm{~J} ., \\
172 \mathrm{~cm}, 87 \mathrm{~kg}\end{array}$ & 3,85 & 996 & 2,2 & 35,6 & 0,78 & $\begin{array}{l}\text { Rezidiv. chromophob. Adenom in den Hypothala- } \\
\text { mus wachsend. Keine sek. NNR-Insuffizienz, sek. } \\
\text { Hypothyreose, sek. Hypogonadismus. } \\
\text { Sella vergrößert, Chiasmasyndrom }\end{array}$ \\
\hline
\end{tabular}


Tabelle 3. Akromegalie

\begin{tabular}{|c|c|c|c|c|c|c|}
\hline & $\begin{array}{l}\text { Basal- } \\
\text { TSH } \\
(\mu \mathrm{U} / \mathrm{ml})\end{array}$ & $\begin{array}{l}\int_{0}^{120} \Delta \mathrm{TSH} \\
(\mu \mathrm{U} / \mathrm{ml} \times \min )\end{array}$ & $\begin{array}{l}\mathrm{PB}^{127 \mathrm{I}} \\
(\mu g-\%)\end{array}$ & $\begin{array}{l}\text { f. } \mathrm{T}{ }^{125} \mathrm{~J} \\
(\%)\end{array}$ & $\begin{array}{l}\mathrm{PBI} \times \mathrm{T}_{3} \\
(\mu \mathrm{g}-\%)\end{array}$ & Diagnosen und Angaben zur Klinik \\
\hline \multicolumn{7}{|c|}{ a) Aktive } \\
\hline $\begin{array}{l}\text { G. A., O, } 31 \mathrm{~J} ., \\
182 \mathrm{~cm}, 90 \mathrm{~kg}\end{array}$ & 4,75 & 408 & 4,2 & 42,1 & 1,77 & $\begin{array}{l}\text { aktive Akromegalie, keine sek. NNR-Insuffizienz, } \\
\text { keine sek. Hypothyreose, keine Struma, sek. Hypo- } \\
\text { gonadismus. } \\
\text { Sella vergrößert, kein Chiasmasyndrom }\end{array}$ \\
\hline $\begin{array}{l}\text { Sch. F., o, } 38 \mathrm{~J} ., \\
185 \mathrm{~cm}, 103 \mathrm{~kg}\end{array}$ & 5,40 & 1823 & 7,0 & 33,5 & 2,35 & $\begin{array}{l}\text { aktive Akromegalie, keine sek. NNR-Insuffizienz, } \\
\text { keine sek. Hypothyreose, kleine Struma, sek. Hypo- } \\
\text { gonadismus. } \\
\text { Sella vergrößert, kein Chiasmasyndrom }\end{array}$ \\
\hline $\begin{array}{l}\text { W. T., }, 58 \mathrm{~J} ., \\
168 \mathrm{~cm}, 74 \mathrm{~kg}\end{array}$ & 3,90 & 424 & vers. & 35,4 & - & $\begin{array}{l}\text { aktive Akromegalie, keine sek. NNR-Insuffizienz, } \\
\text { keine sek. Hypothyreose, keine Struma, kein sek. } \\
\text { Hypogonadismus. } \\
\text { Sella vergrößert }\end{array}$ \\
\hline $\begin{array}{l}\text { P. T., }+, 44 \mathrm{~J} ., \\
160 \mathrm{~cm}, 67 \mathrm{~kg}\end{array}$ & 14,9 & 11775 & 3,2 & 29,5 & 0,94 & $\begin{array}{l}\text { aktive Akromegalie, keine sek. NNR-Insuffizienz, } \\
\text { strumiprive Hypothyreose, kein sek. Hypogonadis- } \\
\text { mus. } \\
\text { Sella vergrößert }\end{array}$ \\
\hline $\begin{array}{l}\text { L. Ch., , } 39 \mathrm{~J} ., \\
171 \mathrm{~cm}, 119 \mathrm{~kg}\end{array}$ & 3,9 & 778 & 4,8 & 27,4 & 1,32 & $\begin{array}{l}\text { aktive Akromegalie, keine sek. NNR-Insuffizienz, } \\
\text { Verd. sek. Hypothyreose, kleine Struma, sek. Hypo- } \\
\text { gonadismus. } \\
\text { Sella vergrößert }\end{array}$ \\
\hline $\begin{array}{l}\text { R. H., }, \text {, } 46 \mathrm{~J} . \text {, } \\
177 \mathrm{~cm}, 71 \mathrm{~kg}\end{array}$ & 7,70 & 1687 & 4,8 & 29,3 & 1,41 & $\begin{array}{l}\text { aktive Akromegalie, keine sek. NNR-Insuffizienz, } \\
\text { keine sek. Hypothyreose, Zustd. nach Struma- } \\
\text { resektion, Verdacht sek. Hypogonadismus. } \\
\text { Sella vergrößert }\end{array}$ \\
\hline $\begin{array}{l}\text { R. F., ऊ, } 48 \text { J., } \\
181 \mathrm{~cm}, 109 \mathrm{~kg}\end{array}$ & 7,80 & 1892 & 2,6 & 26,1 & 0,68 & $\begin{array}{l}\text { Rezidiv einer aktiven Akromegalie, keine sek. NNR- } \\
\text { Insuffizienz, strumiprive Hypothyreose, sek. Hypo- } \\
\text { gonadismus. } \\
\text { Sella vergrößert, Chiasmasyndrom }\end{array}$ \\
\hline
\end{tabular}

\begin{tabular}{|c|c|c|c|c|c|c|}
\hline \multicolumn{7}{|c|}{ b) Behandelte } \\
\hline $\begin{array}{l}\text { R. F., ô, } 48 \mathrm{~J}, \\
181 \mathrm{~cm}, 109 \mathrm{~kg}\end{array}$ & 6,10 & 613 & 4,4 & 31,2 & 1,37 & $\begin{array}{l}\text { Zustand nach Operation eines Rezidivs einer Akro- } \\
\text { megalie, keine sek. NNR-Insuffizienz, strumiprive } \\
\text { Hypothyreose, sek. Hypogonadismus. } \\
\text { Sella vergrößert, Chiasmasyndrom }\end{array}$ \\
\hline $\begin{array}{l}\text { O. S., §, 62 J., } \\
181 \mathrm{~cm}, 76 \mathrm{~kg}\end{array}$ & 3,45 & 92 & vers. & 31,0 & - & $\begin{array}{l}\text { Zustand nach }{ }^{90} \mathrm{Y} \text {-Implantation wegen Akromegalie, } \\
\text { HVL-Insuffizienz, LATS pos. Hyperthyreose mit } \\
\text { Ophthalmopathie, Zustand n. Strumaresektion. } \\
\text { Sella vergrößert }\end{array}$ \\
\hline $\begin{array}{l}\text { L. G., J, } 32 \mathrm{~J} ., \\
181 \mathrm{~cm}, 85 \mathrm{~kg}\end{array}$ & 51,00 & 5765 & 4,2 & 38,7 & 1,63 & $\begin{array}{l}\text { Zustand nach Operation der Akromegalie, keine sek. } \\
\text { NNR-Insuffizienz, keine sek. Hypothyreose, Struma } \\
\text { eben tastbar. Sek. Hypogonadismus. } \\
\text { Sella vergrößert, kein Chiasmasyndrom }\end{array}$ \\
\hline $\begin{array}{l}\text { H. O., } 954 \mathrm{~J} . \\
150 \mathrm{~cm}, 78 \mathrm{~kg}\end{array}$ & 2.95 & 83 & 4.0 & 23.8 & 0.95 & $\begin{array}{l}\text { Zustand nach Operation der Akromegalie, sek. NNR- } \\
\text { Insuffizienz, sek. Hypothyreose, kleine diffuse } \\
\text { Struma, sek. Hypogonadismus. Sella vergrößert, } \\
\text { kein Chiasmasyndrom }\end{array}$ \\
\hline $\begin{array}{l}\text { R. H., }, 18 \mathrm{~J} ., \\
175 \mathrm{~cm}, 110 \mathrm{~kg}\end{array}$ & 4,50 & 247 & 4,6 & 26,7 & 1,23 & $\begin{array}{l}\text { Zustand nach Operation der Akromegalie, fragliche } \\
\text { sek. NNR-Insuffizienz, sek. Hypothyreose, sek. } \\
\text { Hypogonadismus }\end{array}$ \\
\hline $\begin{array}{l}\text { G. A., } 0,31 \mathrm{~J} ., \\
182 \mathrm{~cm}, 90 \mathrm{~kg}\end{array}$ & 2,20 & 324 & 4,0 & 42,7 & 1,71 & $\begin{array}{l}\text { Zustand nach transsphenoidaler Operation der Akro- } \\
\text { megalie, keine sek. NNR-Insuffizienz, keine sek. } \\
\text { Hypothyreose, keine Struma, kein sek. Hypogona- } \\
\text { dismus. } \\
\text { Sella vergrößert, kein Chiasmasyndrom }\end{array}$ \\
\hline
\end{tabular}


Tabelle 4. Primäre Hypothyreose

\begin{tabular}{|c|c|c|c|c|c|c|}
\hline & $\begin{array}{l}\text { Basal- } \\
\text { TSH } \\
(\mu \mathrm{U} / \mathrm{ml})\end{array}$ & $\begin{array}{l}\int_{0}^{120} \Delta \mathrm{TSH} \\
(\mu \mathrm{U} / \mathrm{ml} \times \mathrm{min})\end{array}$ & $\begin{array}{l}\mathrm{PB}^{127 \mathrm{I}} \\
(\mu \mathrm{g}-\%)\end{array}$ & $\begin{array}{l}\text { f. } \mathrm{T}_{3}{ }^{-125} \mathrm{~J} \\
(\%)\end{array}$ & $\begin{array}{l}\mathrm{PBI} \times \mathrm{T}_{3} \\
(\mu g-\%)\end{array}$ & Diagnosen und Angaben zur Klinik \\
\hline $\begin{array}{l}\text { Gr. H., } 0,34 J . \\
160 \mathrm{~cm}, 60 \mathrm{~kg}\end{array}$ & 35,75 & 3321 & 1,2 & 32,6 & 0,39 & Primäre Hypothyreose bei Zungengrundstruma \\
\hline $\begin{array}{l}\text { K. E., }, 36 \mathrm{~J} ., \\
171 \mathrm{~cm}, 70 \mathrm{~kg}\end{array}$ & 3,75 & 2661 & 4,0 & 32,1 & 1,28 & $\begin{array}{l}\text { Verdacht auf präklinische Hypothyreose, keine } \\
\text { Struma }\end{array}$ \\
\hline
\end{tabular}

Mittelwert mit einfacher Standardabweichung beträgt $\int_{1}^{120} \Delta \mathrm{TSH}=65 \mathrm{~L} \pm 373 \mu \mathrm{U} \times \mathrm{ml}^{-1} \times \min . \quad-$ Basale TSH-Spiegel und TSH-Anstieg nach TRE sind bei den je 4 Normalpersonen mit und ohne kleine diffuse Struma nicht verschieden.

Die beiden untersuchten Patienten mit einer primären Hypothyreose (G. H. und K. E.) zeigen wie aus der Literatur bekannt $[6-8]$, eine erheblich stärkere Stimulation der TSH-Sekretion durch TRF als die Normalpersonen (Abb. 2, 3 und Tabelle 4). Diese Patienten sind hier aufgeführt, um den Vergleich von primärer Hypothyreose einerseits and hypophysärer, bzw. hypothalamischer sekundärer Hypothyreose andererseits zu ermöglichen.

\section{Vorwiegend intrasellär wachsende Hypophysentumoren}

Die Gruppe der Patienten $(N=9)$ mit einem hormonell inalitiven Adenom des Hypophysenvorderlappens, welches in 8 Fällen nach der TRF-Belastung operativ gesichert wurde, zeigt einen normalen Anstieg der Serum-TSH-Spiegel nach Stimulation durch TRE sowohl $30 \mathrm{~min}$ nach der Injektion (Abb. 3), als auch bei Berücksichtigung aller Werte als Integral bis zur 120. $\min (\mathrm{Abb} .2)$. Die Stimulation der TSH-Sekretion dieser Gruppe durch TRE läßt keine Unterscheidung von den Normalpersonen zu. Wichtig ist, daß 3 dieser Patienten eine sekundäre Hypothyreose haben (Tabelle 1a).

Klinisch am ausgeprägtesten war die sekundäre Hypo. thyreose bei dem Patienten F. G. (Tabelle 1 a, Abb. 2, 3). Die Diagnose eines vorwiegend intraselllär wachsenden HVLAdenoms konnte in diesem Fall nicht gesichert werden (Operationsverweigerung). Die weite Sella, die komplette HVL. Insuffizienz und das Fehlen des Diabetes insipidus veranlassen uns jedoch zu dieser Diagnose. Auch die nicht erhöhten TSH. Spiegel vor und 24 Std nach TRF sprechen gegen eine primäre Hypothyreose.

Patienten, die wegen eines hormonell inaktiven $H V L$-Adenoms operiert worden waren $(N=8)$, weisen einen verminderten Anstieg der TSH-Spiegel nach Stimulation durch TRF auf (Abb.2, Tabelle 1b). Auch 30 min nach Injektion von TRF (Abb. 3) exreicht keiner dieser Patienten einen normalen Anstieg der TSH-Spiegel. Die Mittelwerte $(\tilde{x} \pm \xi)$ der TSHSpiegel vor und 30 min nach TRF sind $3,48 \pm 0,71$ $\mu \mathrm{U} / \mathrm{ml}$ bzw. $5,02 \pm 1,24 \mu \mathrm{U} / \mathrm{ml}$. Sechs dieser $8 \mathrm{~Pa}$ tienten haben eine sekundäre Hypothyreose.
Die beiden euthyreoten Patienten S. H. und W. E. wurden vor und 6 Wochen nach der Operation untersucht: S. H. hatte ein antonomes Adenom der Schilddrüse. Seine basalen TSHSpiegel fielen von $4,70 \mu \mathrm{U} / \mathrm{ml}$ auf postoperativ $1,85 \mu \mathrm{U} / \mathrm{ml}$, das Integral der TSH-Spiegel sank von $508 \mu \mathrm{U} \times \mathrm{ml}^{-1} \times$ min auf $213 \mu \mathrm{U} \times \mathrm{ml}^{-1} \times \min \mathrm{ab}$, während der Index des freien Schilddrüsenhormons von $2,18 \mu \mathrm{g} / 100 \mathrm{ml}$ auf den noch euthyreoten Wert von $1,47 \mu \mathrm{g} / 100 \mathrm{ml}$ abfiel. Das autonome Adenom der Schilddrüse ist wohl als Ursache für die noch euthyreote Stoffwechsellage trotz HVL-Insuffizienz [18] anzusehen, wobei postoperativ die sekundäre NNR-Insuffizienz und der sekundäre Hypogonadismus nachweisbar sind - W. E. zeigte zwar noch keinen Abfall der basalen TSH-Spiegel, jedoch schon eine deutliche Verminderung der Stimulierbarkeit der TSH-Ausschüttung durch TRF (Tabelle $1 \mathrm{a}, \mathrm{b}$ ).

In der Gruppe der Patienten mit intrasellär wachsendem Kraniopharyngeom, die schon operiert worden waren $(N=4)$, ist die TSH-Sekretion in keinem der Fälle durch TRF stimulierbar $(\mathrm{Abb}, 2,3)$. Eine Patientin mit sekundärer NNR-Insuffizienz und primärer Amenorrhoe (K. R.) hat jedoch gerade noch normale Schilddrüsenhormonspiegel im Blut (Tabelle $1 \mathrm{c})$.

\section{Vorwiegend suprasellär wachsende Kraniopharyn- geome und hypothalamische Erkrankungen}

Zwei Patienten (Abb. 2, 3), M. J. und F. U., mit operiertem Kraniopharyngeom haben eine vorwiegend supraselläre Tumorausdehung mit sekundärer Hypothyreose (Tabelle 2a).

Die TSH-Ausschütung von F.U. ist 30 min nach TRF subnormal (Abb. 3), erreicht aber bei Integration der TSHAusschüttung über $120 \mathrm{~min}$ gerade normale Werte (Abb. 2 u. 4). - Der Verlauf der TSH-Sekretion der Patientin M. J., die außer der sekundären Hypothyreose eine primäre Amenorrhoe und einen HGH-Mangel, jedoch keine sekundäre NNR. Insuffizienz hat, findet sich in Abb. 4. Der basale TSH-Spiegel ist normal, nach TRF kommt es zu einem auffallend hohen Anstieg (Abb. 2). Auch hier bleiben die TSH-Spiegel zwischen der 20. und 120. min hoch (Abb. 4). Das Maximum findet sich in der 30. min nach der Injektion von TRF.

Die Patienten mit hypothalamischen Erkrankungen $(N=5)$ und einer sekundären Hypothyreose zeigen außer einem (H. G.) eine durch TRF stimulierbare TSH-Sekretion (Abb. 2). Bei dieser einen Ausnahme handelt es sich um einen Patienten, der wegen eines inoperablen himeigenen hypothalamischen Tumors erfolgreich bestrahlt wurde. Er hat eine vollständige HVL-Insuffizienz und einen Diabetes insipidus.

Der Patient v. M. A. leidet an einer Arachnitis opticochiasmatica mit partiellem Diabetes insipidus und cerebraler Hyperosmolalität (Tabelle $2 \mathrm{~b}$ ). Bei der ersten Belastung mit 


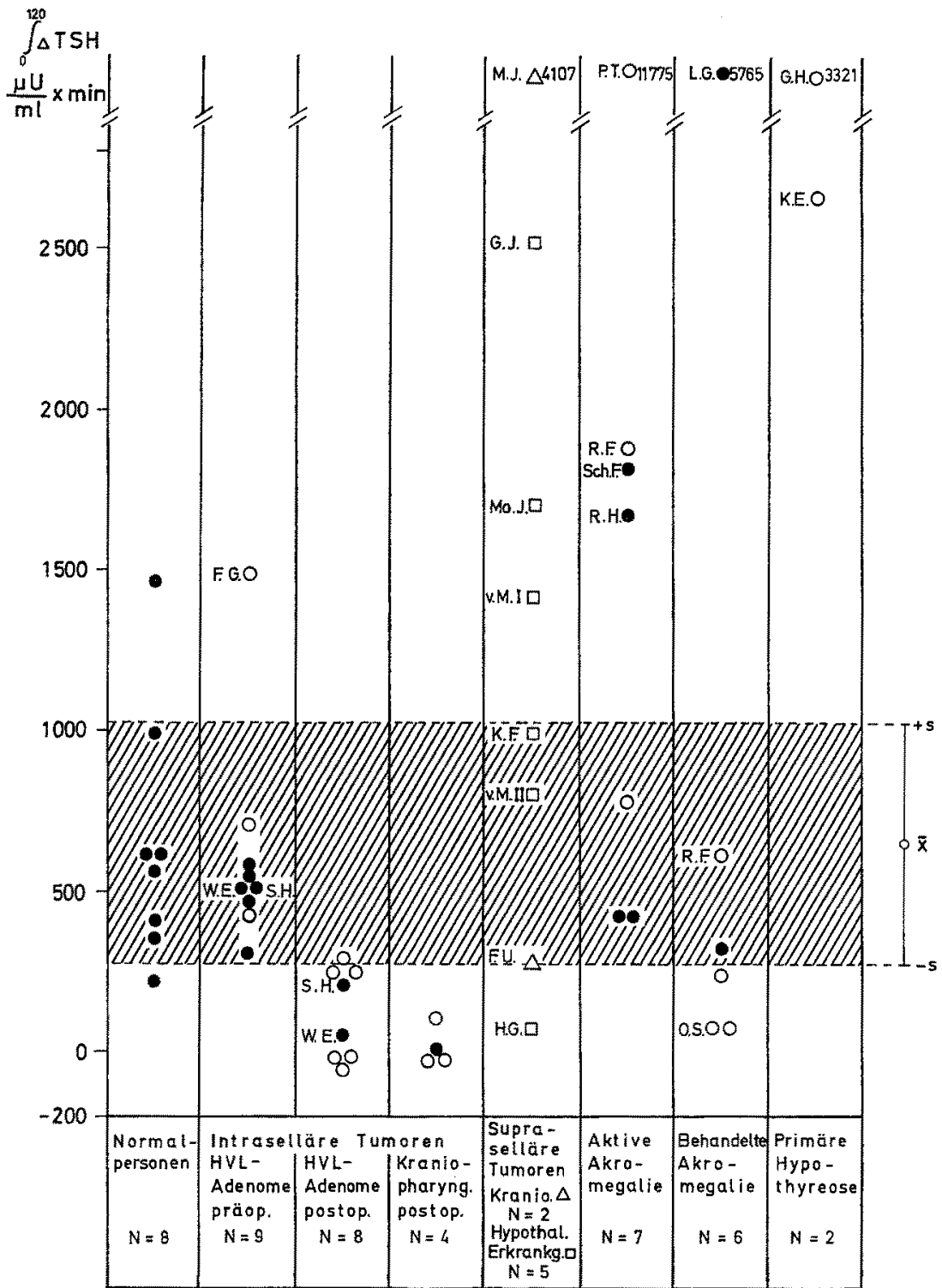

Abb. 2. Anstieg der individuellen TSH-Spiegel nach Injektion von $500 \mu \mathrm{g}$ TRF. Von dem Integral unter der Kurve der TSHWerte von 0-120 min nach der Injektion wurde das Produkt aus mittlerem basalen TSH-Spiegel (15 min und 5 min vor der $120 \quad$ Injektion) und der Zeit (120 min) abgezogen: $\int_{0}^{120} \mathrm{TSH}-\int_{0}^{120}$ Basal-TSH $=\int_{0}^{120} 4 \mathrm{TSH}\left[\mu \mathrm{U} \times \mathrm{ml}^{-1} \times \mathrm{min}\right]$. Die Berechnung erfolgte mit einem Tischcomputer (Olivetti, Programma 102). Sohraffiert ist der TSH-Anstieg der 8 Normalpersonen angegeben $(\bar{x} \pm s): \int_{0}^{120} \Delta \mathrm{TSH}_{\text {normal }}=651 \pm 373 \mu \mathrm{U} \times \mathrm{ml}^{-1} \times \mathrm{min}$. Euthyreote Personen haben geschlossene Symbole, mit offenen Symbolen wurden hypothyreote Patienten ohne Rücksicht auf die Genese der Hypothyreose gekennzeichnet. Einzelheiten über Patienten, deren Symbole mit Initialen versehen sind, sind den Tabellen 1-4 und dem Text zu entnehmen

TRF zeigte er eine erhöhte Stimulierbarkeit der TSH-Sekretion (Abb. 2-4). Bei einer zweiten Belastung, bereits unter Cortisol-Substitution und Tegretal@-Behandlung, welche die vorher beim Durstversuch erniedrigte Urinosmolalität normalisierte, ist die Stimulierbarkeit der TSH-Sekretion normal.

Der Patient G. J. (Tabelle 2b) hat einen sekundären Hypogonadisraus, eine latente NNR-Insuffizienz, sowie eine sekundäre Hypothyreose. Die normal große Sella und ein normales Pneumencephalogramm lassen eine symptomatische HVL-Insuffizienz bei bisher nicht geklärter hypothalamischer Erkrankung diagnostizieren. In diesem Fall zeigt die Kinetik der TSH-Ausschüttung das Maximum bei $30 \mathrm{~min}$ nach TRF (Abb.4). Der PB ${ }^{127} I-W e r t$ stieg bei der TSH-Belastung von 2,7 auf $4,8 \mu \mathrm{g} / 100 \mathrm{ml}$ an. 
$\triangle T S H$

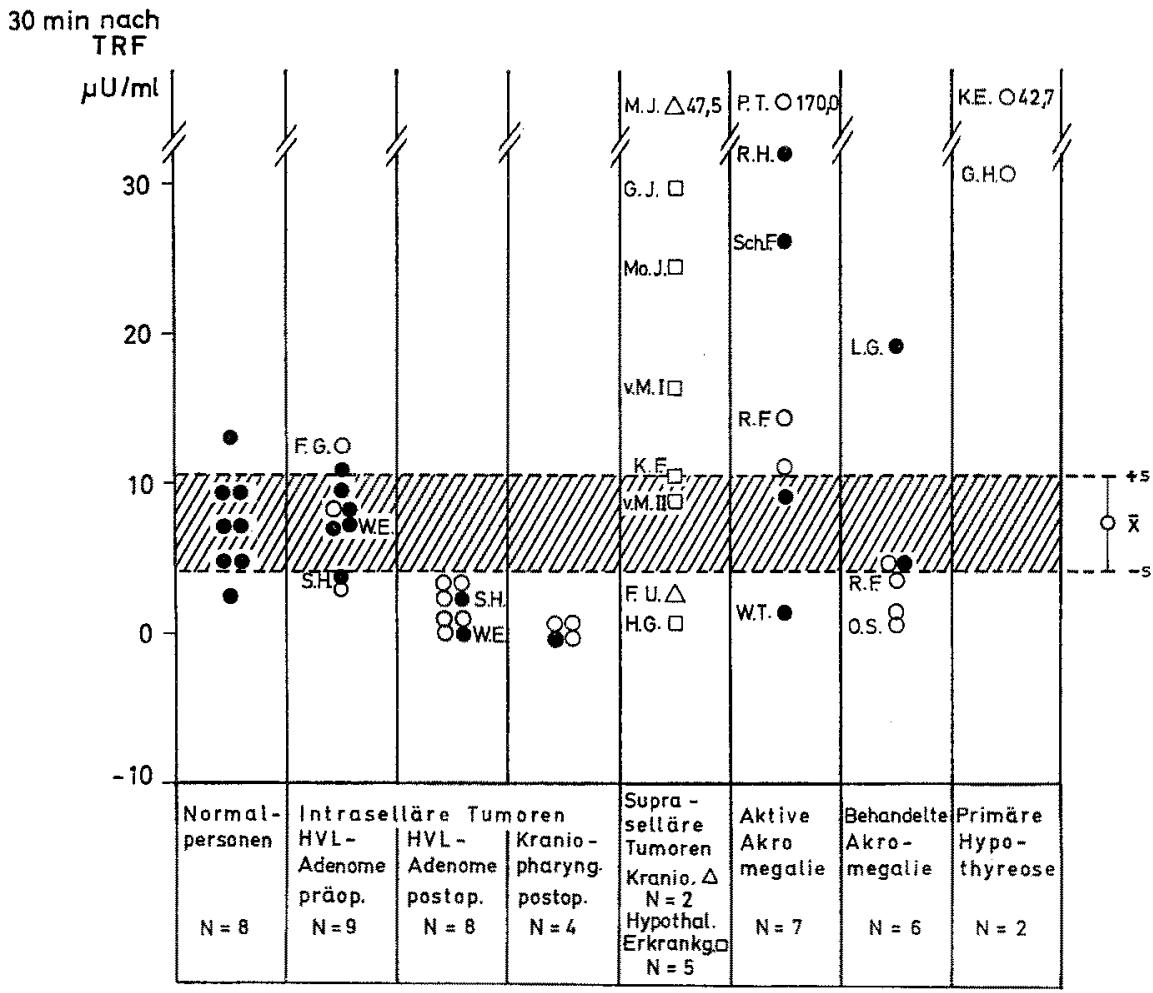

Abb. 3. Anstieg der TSH-Spiegel ( $\triangle \mathrm{TSH}$ ) $30 \mathrm{~min}$ nach Injektion von $500 \mu \mathrm{g}$ TRF, ausgehend vom Mittelwert der beiden Nüchternwerte $15 \mathrm{~min}$ und $5 \mathrm{~min}$ vor der Injektion (basale TSH-Spiegel). Offene und geschlossene Symbole wurden verwendet wie in $\mathrm{Abb} .2$

Die Patientin Mo. J., bei der eine sekundäre Hypothyreose und ein Hypogonadismus bei normaler Nebennierenrindenfunktion, normaler Sella und intaktem Visus bestehen, erreicht das Maximum der TSH-Sekretion bereits nach $20 \mathrm{~min}$ (Abb.4). Eine primäre Hypothyreose wurde durch den ${ }^{131}$ Jod-Speicherungstest und die Bestimmung der Schilddrüsenhormone vor und nach exogener Stimulation durch TSH ausgeschlossen (PB' ${ }^{127} \mathrm{I}: 1,6 \mu \mathrm{g} / 100 \mathrm{ml}$ vor und $4,8 \mu \mathrm{g}$ ) $100 \mathrm{ml}$ nach TSH-Belastung).

Der Patient K. F. war an einem chromophoben HVL Adenom operiert worden und entwickelte in den folgenden Jahren eine sekundäre Hypothyreose. Die Diagnose wurde anhand der peripheren Schilddrüsenhormonwerte und der ${ }^{131}$ Jod-Speicherung vor und nach exogener TSH-Stimulation gestellt, welche eine primäre Hypothyreose ausschließen ließen. Trotz dieser von uns zunächst als hypophysär gedeuteten sekundären Hypothyreose [11] war die TSH-Aus. schüttung durch TRF deutlich stimulierbar (Abb. 2,3). Die TSH-Spiegel dieses Patienten blieben während der gesamten Untersuchungszeit hoch, die Ausgangswerte sind auch nach 24 Std noch nicht wieder erreicht (Abb. 4). Der weitere Verlauf der Erkrankung dieses Patienten zeigte ein Tumor. Rezidiv, das in den Hypothalamus vordrang. Er starb an einer Blockade des Foramen Monroe. Daher muß seine sekundäre Hypothyreose als hypothalamisch bedingt aufgefaßBt werden.

Bei 4 von 7 Patienten mit suprasellären Tumoren bzw. hypothalamischen Erkrankungen (v. M. A. bei beiden Untersuchungen, bei G. J., M. J. und K. F.) ist der TSH-Spiegel nach Injektion von TRF zur 60. min höher als zur 20. $\min (\mathrm{Abb} .4)$.

\section{Akromegalie}

In der Gruppe der aktiven Akromegalien $(N=7)$ zeigen euthyreote Patienten ohne Struma eine normale Stimulierbarkeit der TSH-Ausschüttung (Abb.2, 3). Drei Patienten mit niedrigen Schilddrüsenhormonspiegeln (R. H., R. F. und P.T.) nach Strumaresektion weisen eine stärkere Stimulierbarkeit der TSHSekretion durch TRF als die Normalpersonen auf und haben bereits erhöhte TSH-Basalspiegel (Tabelle 3a). Ein euthyreoter Patient (Sch. F.) mit einer blanden Struma hat gleichfalls eine erhöhte TSH-Sekretion. nach TRF-Belastung.

Die Stimulierbarkeit der TSH-Sekretion ist in der Gruppe der behandelten Akromegalen $(N=6)$ deutlich vermindert (Abb. 2, 3).

Eine Ausnahme bildet der Patient L. G., der bei euthyreoter Stoffwechsellage und nicht vergrößerter Schilddrüse bereits erhöhte basale TSH-Spiegel (Tabelle $3 \mathrm{~b}$ ) und eine gesteigerte Stimulierbarkeit aufweist. Thyreoglobulin-Antikörper sind nicht nachweisbar. Die postoperativ noch erhöhten HGH-Spiegel lassen in diesem Fall vermuten, daß die Akromegalie Klinisch zwar gebessert, aber noch aktiv ist. - ErwartungsgemäB ist der TSH-Spiegel eines Patienten, welcher wegen seiner Akromegalie eine ${ }^{90}$ Yttrium-Implantation erhalten hatte und danach bei HVL-Insuffizienz einen LATSpositiven Morbus Basedow mit sehwirrender Struma und beidseitigem Exophthalmus entwickelte [18], nicht durch TRF zu stimulieren (O. S., Tabelle $3 \mathrm{~b}$ ). 


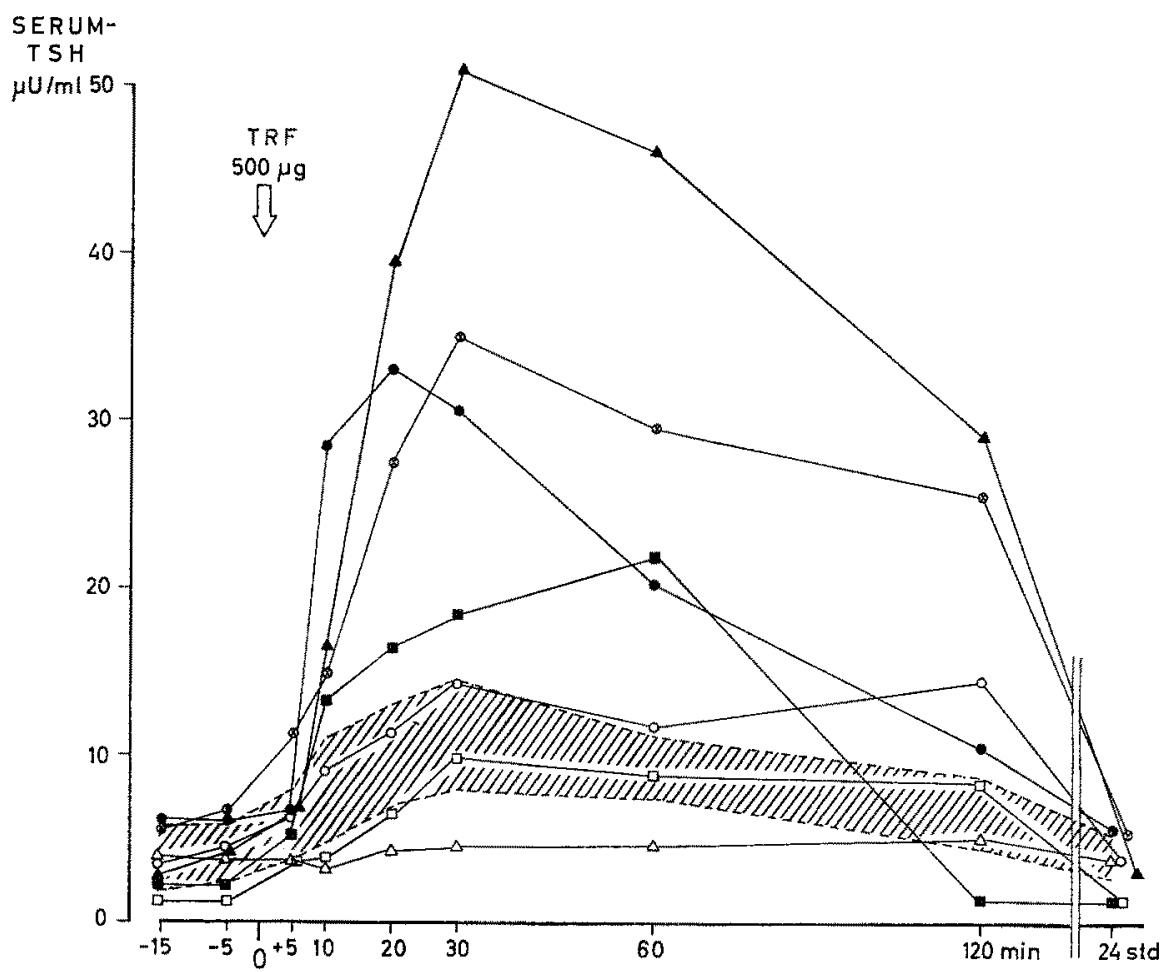

Abb 4. Kinetik der TSH-Spiegel bei Patienten mit hypothalamischen Erkrankungen nach Stimulation durch TRF Schraffiert: Mittelwert \pm einfache Standardabweichung $\bar{x} \pm s)$ von Normalpersonen $(N=8)$. - v. M. A., 1 . Test,

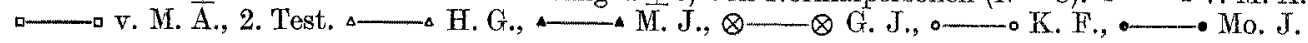

\section{Diskussion}

Der synthetische Thyrotropin Releasing Factor (TRF) wird heute meist Thyrotropin Releasing Hormone (TRH) genannt. Man bringt mit dieser Umbenennung die Auffassung zum Ausdruck, daß der synthetische TRF mit dem extraktiv gewonnenen TRH und mit dem in den Portalgefäßen des Hypophysenstiels zirkulierenden hypophyseotropen Hormon identisch ist. Der direkte Beweis für die Identität des zirkulierenden Hormons (TRH) und des synthetischen TRF steht jedoch noch aus. Außerdem wurde kürzlich über ein noch wirksameres TRF, das 3-Methyl-TRF [19] berichtet. Aus diesen Gründen bevorzugen wir z.Zt. noch die Bezeichnung TRF.

Die Kinetik des TSH-Anstieges nach TRF-Belastung zeigen Abb. 1 und 4. Normalpersonen erreichen das Maximum in der 30. min oder fräher (Tabelle 5). Hall [6] fand, daß bei Patienten mit hypothalamischen Erkrankungen im Gegensatz zu Normalpersonen der 60 min-Wert des TSH-Spiegels höher als der 20 minWert war. Ebenso verhielten sich die Werte von 4 unserer 7 Patienten mit hypothalamischen Erkrankungen (Abb. 4). Wir fanden allerdings auch bei den Patienten mit Hypophysentumoren das Maximum des TSH-Anstiegs nur z.T. zur 30. min. Spätere Maxima hatten 12 von 34 Patienten, frühere 5 von $34 \mathrm{~Pa}$ tienten (Tabelle 5). Eine differentialdiagnostische $\mathrm{Be}$ deutung kommt diesem Kriterium daher nicht zu. Bei diesen zeitlichen Unterschieden der Maxima versprach aber die Erfassung der gesamten TSH-Antwort eine bessere diagnostische Brauchbarkeit des Tests (Abb. 2).

Die $A b b .2$ und 3 vergleichen die diagnostische Wertigkeit der TRF-Belastung bei Erfassung der gesamten TSH-Antwort bis zur 120. min einerseits und bei alleiniger Berücksichtigung des TSH-Anstiegs zur 30. min andererseits. Die Aussage der TSH-Anstiege weicht im Einzelfall bei den beiden Auswertungsverfahren nur gering voneinander ab. Für routinemäßige TRF-Belastungen wird man daher mit der Bestimmung des TSH-Spiegels 30 min nach TRF-Injektion auskommen [8]. Besser lassen sich lediglich verspätete sehr hohe TSH-Anstiege bei einzelnen $\mathrm{Pa}$ tienten erfassen.

Nach Hypophysektomie wegen eines intrasellären HVL-Adenoms oder Kraniopharyngeoms fand sich erwartungsgemäß regelmäßig eine Verminderung oder ein Ausbleiben des TSH-Anstiegs nach TRF-Injektion (Abb. 2, 3). Dabei hatten 3 dieser 12 Patienten noch keine sekundäre Hypothyreose, vgl. Ergebnisse (Tabelle $1 \mathrm{~b}, \mathrm{c}$ ). Die sekundäre Hypothyreose bei operiertem Hypophysentumor ist wohl häufiger als früher mitgeteilt $(51 \%)[20]$.

Besondere Aufmerksamkeit verdienen die normalen TSH-Anstiege nach TRF-Belastung bei noch nicht operierten Patienten mit hormonell inaktivem 
Tabelle 5. Zeitpunkt der Maxima des TSH-Anstiegs nach Stimulation durch TRF.

Die erste Zeile gibt an, wieviele der untersuchten Patienten 30 min nach TRF das Maximum des TSH-Anstiegs erreichten. Das früheste Maximum wurde $20 \mathrm{~min}$ nach TRF erreicht; die zweite Zeile zeigt den spätesten Zeitpunkt der TSH-Maxima an.

\begin{tabular}{|c|c|c|c|c|c|c|c|c|}
\hline & $\begin{array}{l}\text { Normal- } \\
\text { personen }\end{array}$ & $\begin{array}{l}\text { Hormonell } \\
\text { inaktive } \\
\text { HVL- } \\
\text { Adenome } \\
\text { präoperativ }\end{array}$ & $\begin{array}{l}\text { Hormonell } \\
\text { inaktive } \\
\text { HVL- } \\
\text { Adenome } \\
\text { postoperativ }\end{array}$ & $\begin{array}{l}\text { Intrasell. } \\
\text { Kranio- } \\
\text { pharyngeome } \\
\text { postoperativ }\end{array}$ & $\begin{array}{l}\text { Suprasell. } \\
\text { Kranio- } \\
\text { pharyngeome } \\
\text { postoperativ }\end{array}$ & $\begin{array}{l}\text { Hypo- } \\
\text { thalami- } \\
\text { sohe } \\
\text { Erkran- } \\
\text { kungen }\end{array}$ & $\begin{array}{l}\text { Aktive } \\
\text { Akro- } \\
\text { megalie }\end{array}$ & $\begin{array}{l}\text { Be- } \\
\text { handelte } \\
\text { Akro- } \\
\text { megalie }\end{array}$ \\
\hline $\begin{array}{l}\text { Maxima des TSH- } \\
\text { Anstiegs } 30 \mathrm{~min} \text { nach TRF }\end{array}$ & $F^{5 / 8}$ & $6 / 9$ & $4 / 8$ & $1 / 4$ & $1 / 2$ & $3 / 6$ & $5 / 7$ & $1 / 6$ \\
\hline $\begin{array}{l}\text { Spätestes Maximum } \\
\text { nach 'TRF (min) }\end{array}$ & 30 & 60 & 120 & 24. Std & 120 & 120 & 120 & 120 \\
\hline
\end{tabular}

HVL-Adenom (Abb. 2, 3). Von diesen 9 Patienten hatten zwar erst 3 eine sekundäre Hypothyreose. Man muß wegen dieser 3 Patienten aber folgern, daß ein Anstieg der Serum-TSH-Spiegel nach TRF-Belastung die hypophysäre Genese einer sekundären Hypothyreose nicht mit Sicherheit ausschließt. Die Interpretation dieses Befundes muß hypothetisch bleiben. Bei hypophysär bedingter sekundärer Hypothyreose erwartet man eine erhöhte Sekretion von endogenem TRH. Es ist denkbar, daß dieses TRH den Hypophysenvorderlappen nicht mehr über die Portalgefäße des Hypophysenstiels erreicht (mechanische Zirkulationsstörung) und daß die basale TSH. Selkretion nicht mehr ausreicht, um eine Euthyreose zu unterhalten. Eine große exogene TRF-Dosis kann dagegen möglicherweise auf arteriellem Wege noch zum Hypophysenvorderlappen gelangen und so zu einer Steigerung der TSH-Ausschüttung führen.

Bei suprasellären Tumoren und hypothalamischen Erkrankungen fand sich erwartungsgemäB ein normaler, in einigen Fällen ein erhöhter Anstieg der TSHSpiegel nach TRF-Belastung (Ausnahmen: H. G. und F. U., Tabelle $2 a, b$ ). Für den erhöhten TSH-Anstieg nach TRF-Belastung könnte man als eine Erklärungsmöglichkeit diskutieren, daß es bei Fortfall des endogenen TRH zu einem „Aufstau" von TSH im Hypophysenvorderlappen kommt. Eine primäre Нypothyreose (Tabelle 4, Abb. 2, 3), welche ebenfalls durch einen über die Norm erhöhten TSH-Anstieg gekennzeichnet ist $[6,7]$, wurde in diesen Fällen ausgeschlossen.

Eine diagnostische Bedeutung kann die TRF-Belastung bei Fällen von sekundärer Hypothyreose zur Unterscheidung von hypophysärer und hypothalamischer Erkrankung haben (G. J., Mo. J. und v. M. A., Tabelle 2 b). Wie schwierig die Differentialdiagnose zwischen hypophysärer und hypothalamischer Ursache einer sekundären Hypothyreose aber sein kann, zeigt der Patient K. F. (Tabelle 2 b), vgl. auch Patient F. G. (Tabelle 1a). Dieser Patient (K. F.) hatte ein Rezidiv eines HVL-Adenoms. Es lag daher zunächst nahe, seine sekundäre Hypothyreose als hypophysär bedingt aufzufassen [11]. Dabei störte jedoch der hoch-normale Anstieg des TSH-Spiegels nach TRFBelastung. Die hypothalamische Ursache der sekundären Hypothyreose wurde erst geklärt, als der weitere Verlauf das Eindringen eines Rezidiv-Tumors in den dritten Ventrikel aufzeigte.

Wichtig ist bei der Beurteilung der TRF-Belastung: der Ausschluß einer primären Hypothyreose, auch der ,präklinischen“ Form [6]. Das zeigen die Ergebnisse bei den Akromegalen. Zwei Patienten (R. F. und P.T.) hatten eine strumiprive Hypothyreose (Tabelle 3), so daß der beobachtete erhöhte Anstieg des TSH-Spiegels nach TRF-Injektion als Folge der primären Hypothyreose gedeutet werden muß. Dagegen sind die erhöhten TSH-Anstiege der Patienten Sch. F. (aktive Akromegalie) und L. G. (fraglich aktive Akromegalie, vgl. Tabelle $3 \mathrm{a}$, b) nicht mit einer primären Hypothyreose zu erklären. Hier muß die Frage offen bleiben, ob die Entwicklung der bei der Akromegalie [21] relativ häufig zu beobachtenden Struma durch die gesteigerte HGH-Sekretion (Visceromegalie) oder durch eine Mehrausschüttung von TSH bedingt ist.

\section{Literatur}

1. Folkers, K., Enzmann, F., Bøler, J., Bowers, C. Y., Schally, A. V.: Discovery of modification of the synthetic tripeptide-sequence of the thyrotropin releasing hormone having activity. Biochem. biophys. Res. Commun. 37, $123(1969)$.

2. Bøler, J., Enzmann, F., Folkers, K., Bowers, C. Y., Schally, A. V.: The identity of chemical and hormonal properties of the thyrotropin releasing hormone and pyroglutamyl-histidyl-proline amide. Biochem. biophys. Res. Commun. 37, 705 (1969).

3. Burgus, R., Dunn, T. F., Desiderio, D., Ward, D. N., Vale, W., Guillemin, R.: Characterization of ovine hypothalamic hypophysiotropic TSH-releasing factor. Nature (Lond.) 226, 34 (1970).

4. Bowers, C. Y., Schally, A. V., Enzmann, F., Bøler, J., Folkers, K.: Porcine thyrotropin releasing hormone is (pyro) glu-his-pro $\left(\mathrm{NH}_{2}\right)$. Endocrinology 86, 1143 (1970).

5. Hall, R., Amos, J., Garry, R., Buxton, R. L.: Thyroidstimulating hormone response to synthetic thyrotropin releasing hormone in man. Brit. med. J. 1970II, 274.

6. - The clinical significance of the TRH. Symposium, VIII. Acta endocr. Congr., Copenhagen, 1971. 
7. Mühlen, A. von zur, Hesch, R. D., Emrich, D., Creutzfeldt, W.: Wirkung von synthetischem, thyreotropin releasing factor" auf Plasmaspiegel von thyreotropem Hormon und Wachstumshormon bei Gesunden, Patienten mit Hyperthyreose und primärer Hypothyreose. Dtsch. med. Wschr. 95, 2623 (1970).

8. - Hesch, R. D., Köbberling, J., Emrich, D.: Thyrotrophin Releasing Factor (TRF) in the diagnosis of thyroid disorders: Its application in different states of Graves' diesease. Acta endocr. (Kbh.), Suppl. 155, 6 (1971).

9. Fleischer, N., Burgus, R., Vale, W., Dunn, T., Guillemin, R.: Preliminary observations on the effect of synthetic thyrotropin releasing factor on plasma thyrotropin levels in man. J. clin. Endocr. 31, 109 (1970).

10. - Lorente, M., Hauger-Klevene, J., Calderon, M.: The use of thyrotropin releasing factor as a test of pituitary TSH reserve. Abstract. 53. Meet. Endocr. Soc., San Francisco, 1971.

11. Pickardt, C. R., Geiger, W., Horn, K., Müller, O. A., Souvatzoglou, A., Scriba, P. C.: TRF bei der Diagnostik von hypothalamisch-hypophysären Tumoren. TRF-Symposium, Mainz, 1971 Stuttgart: Schattauer (im Druck).

12. Horn, K., Scriba, P. C.: Klinisch-chemische Schilddrüsenfunktionsdiagnostik. I. Bestimmung des proteingebundenen Jods im Serum (PB $\left.{ }^{127} \mathrm{I}\right)$. Dtsch. Ges. Klin. Chem. Mitt. $(1970)$, No $5,3$.

13. - Henner, J., Scriba, P C.: Klinisch-chemische Schilddrüsenfunktionsdiagnostik. II. Automatisierter $\mathrm{T}_{\mathbf{3}^{-} \text {-in }}$ vitro-Test. Dtsch. Ges. Klin. Chem. Mitt. (1971), No 2, 29.

14. Franchimont, P.: Radio-immunoassay of gonadotropic hormones. In: Protein and polypeptide hormones, ed. M. Margoulies, Excerpta medica foundation, Intern. Congr. Ser. 161, Amsterdam (1968), 99.

15. Geiger, W., Kaiser, R., Franchimont, P.: Comparative radioimmunological determination of $\mathrm{HCG}, \mathrm{HPL}, \mathrm{STH}$ and TSH in fetal and maternal blood after delivery. Acta endocr. (Kbh.) 68, 169 (1971).
16. Souvatzoglou, A., Bottermann, P., Dirr, F,, Pickardt, C. R., Schwarz, K.: "Quantitative" immunochemische LH-Bestimmung im Urin bei Normalpersonen und bei Patienten mit Hypophysentumoren. Klin. Wschr. 49, 215 (1971).

17. Kluge, F., Gerb, A. C., Boss, N., Fahlbusch, R., Seriba, P. C.: Eine verbesserte fluorimetrische Cortisol-Bestimmung im Serum: Diagnostische Bedeutung und therapeutische Folgerungen bei NNR-Insuffizienz. Klin. Wschr. 48, $929(1970)$.

18. Pickardt, C. R., Scriba, P. C.: Schilddrüsenwachstum und Schilddrüsenüberfunktion bei Hypophysenvorderlappeninsuffizienz. Dtsch. med. Wschr. 95, 2166 (1970).

19. Rivier, J., Burgus, R., Vale, W.: 3-Methyl-TRF, a synthetic analogue with specific activity greater than that of TRF. Abstract, 53. Meet. Endocr. Soc., San Francisco, (1971).

20. Scriba, P. C.: Postoperative Diagnostik und Substitutionstherapie bei Hypophysentumoren. Symp. Dtsch. Ges. Endokr. 15, 274 (1969).

21. - Sehwarz, K.: Hypothalamus und Hypophyse. In: W. Siegenthaler, Klinische Pathophysiologie, S. 252 Stuttgart: Thieme 1970.

Dr. med. C. Renate Pickardt

PD Dr. med. Peter C. Scriba.

II. Medizinische Klinik der Universität D-8000 München 15, Ziemssenstraße 1

Deutschland

Dr. med. Walter Geiger

I. Frauenklinik der Universität

D-8000 München 15, Maistraße 11

Deutschland.

Dr. med. Rolf Falbusch

Neurochirurgische Klinik der Universität

D-8000 München 15, Beethovenplatz 2-3

Deutschland. 